\title{
Capital Gains Sensitivity of US BBB-Rated Debt to US Treasury Market: Markov-Switching Analyses
}

\author{
Mariya Gubareva $\mathbb{D}^{1,2}$ and Ilias Chondrogiannis ${ }^{3}$ \\ ${ }^{1}$ ISCAL - Lisbon Accounting and Business School, Instituto Politécnico de Lisboa, Av. Miguel Bombarda, 20, \\ 1069-035 Lisbon, Portugal \\ ${ }^{2}$ SOCIUS/CSG-Research in Social Sciences and Management, Rua Miguel Lupi, 20, 1249-078 Lisbon, Portugal \\ ${ }^{3}$ School of Slavonic and East European Studies, UCL-University College London, 16 Taviton Street, London WC1H OBW, UK \\ Correspondence should be addressed to Mariya Gubareva; mgubareva@iscal.ipl.pt
}

Received 19 May 2020; Accepted 22 July 2020; Published 26 August 2020

Guest Editor: Thiago Christiano Silva

Copyright (c) 2020 Mariya Gubareva and Ilias Chondrogiannis. This is an open access article distributed under the Creative Commons Attribution License, which permits unrestricted use, distribution, and reproduction in any medium, provided the original work is properly cited.

\begin{abstract}
We reexamine the relationship between credit spreads and interest rates from a capital gain perspective of bond portfolio. Capital gain sensitivity between US BBB-rated bonds and Treasury bonds is weak and positive in normal periods, but strong and negative during recessions. In the upward phase of business cycles, changes in interest rates are fully reflected in the bond yields, leaving spreads unchanged, while in the downward phase, rates and spreads move in opposite directions. This alternation between two distinct regimes reconciles a long-standing division in the literature. We then discuss the efficiency of shorting Treasury bonds as a hedging strategy and policy suggestions.
\end{abstract}

\section{Introduction}

The postcrisis monetary policy, which resulted into uncertainty regarding further moves in risk-free interest rates, poses questions on the resilience, profitability, and stability of the international financial system, especially in what concerns the financial health of banks and corporate firms. The recently observed low borrowing costs have allowed financial institutions to clear their budgets but have also limited profits and raised concerns on whether the restructuring of balance sheets and the increase of capital buffers will be enough when interest rates eventually increase. Such an increase is expected to apply pressure on the valuation of assets, particularly for companies with ongoing legacy burdens. Therefore, the historical relationship between risk-free rates and asset valuation becomes a key indicator, both for companies and investors. In addition, the choice of metrics used for assessing this sensitivity plays a vital role in what effects can be captured.

In this paper, we employ capital gains of bond portfolio containing risk-free government and risky BBB- rated nongovernment US securities to evaluate hedging strategies that consist of holding risky and selling risk-free assets. Our motivation for focusing the study on BBBrated bond portfolios is based on their importance for institutional investors, such as pension funds and insurance companies, as the investment guidelines of a vast majority of them allow only very limited exposure to high yield debt securities, while the BBB-rated bonds provide more attractive returns than higher quality investmentgrade instruments. We opt for studying bond portfolio instead of single securities, as for the institutional investors the large aggregates represent the main focus of their activity, contrary to cherry-picking of fixed-income exposures, which in a first place may interest individuals with a rather restricted funding capacities. This aspect also allows us to reduce the necessary computation capacity and still be able to produce valuable investment insights. By using the capital gains metric to study the sensitivity of relatively risky US BBB-rated bonds to risk-free US Treasuries (UST), we show that the relationship between credit spreads and yields of risk-free assets is not constant, 
as suggested by earlier research (e.g., [1-3]), but instead changes between two distinct regimes.

In the first regime, which takes place during normal periods of economic growth, any changes in the yield of riskfree assets are fully mirrored by changes in the yield of investment-grade BBB-rated bonds, keeping credit spreads stable. In that context, spread-to-rate sensitivity is null. From a capital gains perspective, the sensitivity of capital gains of US BBB-rated bonds to the capital gains of UST bonds is positive and equal to one.

In the second regime, which manifests during a recession and a subsequent sharp recovery, capital gains sensitivity turns to be negative. The spreads of US BBB-rated bonds and the yields of UST move in opposite directions due to flightto-quality behavior and a fall in interest rates. Thus, spreadto-rate sensitivity becomes negative.

The large differences among previous results, based on spread-to-rate sensitivity analysis and on different choices of models and data, produce inconclusive answers to questions on the actual dynamics between credit spreads, yields, and interest rates. The literature is broadly separated to papers that identify a negative spread-to-rate relationship [2-5] and research that finds a weak positive or null spread-to-rate sensitivity $[1,6-8]$.

For instance, the Merton [4] structural model is based on contingent claims and implies that the probability of default of a debt issuer is affected by changes in the interest rate. It implies a permanently negative relationship between credit spreads and interest rates. On the other hand, Kamin and von Kleist [6] suggest that changes in the interest rate are passed fully or slightly augmented onto the yield of risky bonds in the context of emerging markets. There is a null or a slightly positive relationship between changes in bond spreads and changes in the risk-free rate. The same pattern is also documented by Eichengreen and Mody [7] for country spread of emerging economies with respect to the US interest rate.

Finding a common denominator between the two aforementioned streams of research on interest rate sensitivity is challenging. Thus, to reconcile a pile of contradictory results, we opt for a different capital gain approach and demonstrate its capacity to provide clearer results over the long-range observation intervals. It is also worth mentioning that the financial crisis caused a radical change in the realworld fundamentals and regulatory frameworks, so to revisit old problems, new techniques allowing for deeper insights are needed. Towards that direction, capital gains sensitivity is able to capture long-term effects better than spread-to-rate sensitivity, as the former directly focuses on the end-ofperiod bottom-line portfolio results, while the latter is usually obtained by averaging of the daily sensitivity figures, which are subject to greater computational uncertainty due to smaller amplitudes of examined changes.

A simple metric of the sensitivity of capital gains rather than the sensitivity of credit spread to risk-free interest rates has been proposed to study the interest rate sensitivity of US corporate debt [9], emerging market sovereign bonds [10], and emerging market corporate fixed-income securities [11]. This paper represents an extension of this line of research to the US BBB-rated debt, enhanced by Markov-switching analysis for rigorous detection of sensitivity regime changes.

The capital gains metric is defined as the change in capital gains of a portfolio containing only US BBB-rated bonds over the corresponding change in capital gains of a portfolio containing only UST. While the connection between risk-free interest rates and risky bond yields unavoidably underlines our work, the main focus, however, lies on the profits or losses of bond portfolio. This approach is not widespread in the main stream of financial analysis and usually is employed when the effects of taxation and tax regulation on the performance of financial assets are discussed because tax legislation usually differentiates between capital gains and interim payments.

It is also worth noting that hedging mid- to long-term exposures, usually classified as hold-to-collect and hold-tocollect-and-sell, may differ from intraday short-term hedge methodologies. Additionally, the differences across the normal and distressed market regimes in the behavior of risk-free and risky bond portfolios suggest that hedging interest rate risk by shorting UST, or equivalently holding an interest rate swap that receives a floating rate for a fixed rate, is rather not a completely efficient strategy.

This paper is further motivated by a series of recent reports from regulatory authorities that show a renewed public interest on the relationship between interest rate risk, asset valuation, and regulatory framework [12-14]; Committee on the Global Financial System (CGFS), 2018). The common denominator of these reports is to enhance a framework of interest rate risk management, as after a prolonged period of historically low interest rates, a general overvaluation of assets may pause dangers for financial stability. In that discussion, the sensitivity of financial assets to changes in yields, spreads, and capital gains plays a central role.

The rest of the paper is structured as follows. Section 2 describes the data and methodology. Section 3 provides the empirical results. Section 4 presents the application of Markov-switching model to confirm the robustness of the empirical results. Section 5 discusses the implications of the capital gains sensitivity approach from the theoretical and practical perspectives. Section 6 concludes the paper.

\section{Data and Methodology}

We use the monthly time series of blended yields and average coupons to model the price dynamics of the US BBBrated and UST bond portfolios on a period from March 2001 to August 2016. Our data come from yield and coupon indices, which are used to model prices and investigate the dynamics of annual capital gains of both US BBB-rated bonds and UST securities. The reason for limiting the analysis to the US nongovernmental BBB bond portfolio and the UST portfolio is rooted in the importance of BBB-rated fixed-income exposures for institutional investors, in general, and insurance companies and pension funds, in particular, due to their attractive risk-return attributes. On the other hand, UST bonds represent investment targets of choice for many investors as they are largely considered to be 
safe-haven investments, which are also commonly employed as proxies for risk-free instruments used for designing diverse hedge strategies. In addition, by limiting the number of indices used in our research, we are able to keep under control the necessary computation capacity and produce valuable investment insights.

For US BBB bonds, we use the Citi Broad InvestmentGrade US Credit BBB Yield to Maturity Local (Bloomberg ticker: S200YL) and the Citi Broad Investment-Grade US Credit BBB Average Coupon Local (Bloomberg ticker: S200CP). The constituent members of the pair of the S200YL and S200CP indices are the same and represent nongovernmental BBB-rated debt issued in the US, which comprises corporate, financial, and municipal issuers. For UST securities, we employ the Citigroup indices: Treasuries Yield to Maturity Local (Bloomberg ticker: SA14YL) and Treasuries Average Coupon Local (Bloomberg ticker: SA14CP). The constituent members of the SA14YL and SA14CP are identic and represent U.S. Treasury bonds, excluding Treasury Bills. We resort to yield and coupon indices to analyze capital gains because there is no price index available with similar length and characteristics and because the focus is on portfolios rather than individual assets. Since interest is not reinvested, a total return index is not necessary. Although herein only the US BBB bonds and UST portfolio are employed, we consider that our findings will hold also for many other portfolios, such as Corporates, Financials, Muni, Emerging Market (EM) Corporates, EM Financial, and EM Sovereigns, among many others.

Our methodology is based on [11], but the focus is on the US market rather than emerging economies. The average price of each portfolio can be calculated by discounting future cash flows of coupons and principals. For simplicity, we assume annual coupon payments, principal redemption at maturity, and a flat yield curve. Bonds that reach maturity or are downgraded are removed from the indices, while newly issued ones are added. In essence, we assume a portfolio that perfectly mimics the composition of the respective index and is continuously rebalanced according to any changes within that index. This assumption is frequently used to study risk minimization strategies for portfolio immunization (e.g., [15]). In our case, the continuous rebalancing happens on a monthly basis.

The price $P_{\text {UST }}$ of a UST portfolio with an investment horizon (residual maturity) $T$, average annual coupon $C_{\mathrm{UST}}$, face value $F_{\mathrm{UST}}$, and yield $y_{\mathrm{UST}}$ is

$$
P_{\mathrm{UST}}=\sum_{i=1}^{T} \frac{C_{\mathrm{UST}}}{\left(1+y_{\mathrm{UST}}\right)^{k}}+\frac{F_{\mathrm{UST}}}{\left(1+y_{\mathrm{UST}}\right)^{T}},
$$

where $y_{\mathrm{UST}}$ is the blended yield given by the SA14YL index and $C_{\mathrm{UST}}$ is the average coupon given by the $\mathrm{SA} 14 \mathrm{CP}$ index. The nominal face value $F_{\text {UST }}$ is set to US\$ 1,000 million.

Capital gain is defined as the difference between the initial price and the final price of the entire portfolio, excluding interim coupon payments over a given period. In essence, the initial price is the price the investor would have to pay to purchase one fraction of the bond index, while the final price is the price at the end of the given period. As the indices are continuously rebalanced, our asset is continuously changing. Since we do not aim to assess the efficiency of rebalancing, the associated transaction costs and costs of carry are ignored. After the historical price series is constructed, the capital gain can be written as

$$
C G_{\mathrm{UST}}(t, H)=P_{\mathrm{UST}}(t+H)-P_{\mathrm{UST}}(t),
$$

where $C G_{\text {UST }}$ stands for the capital gains of the UST portfolio, $t$ is the initial date of the analyzed time interval, and $H$ stands for a time horizon over which the capital gains are assessed. The time horizon is one year, since capital gains of investment funds are transferred at the end of each calendar year [16]. The same approach is also applied for analyzing the capital gains of the US BBB-rated bond portfolio. Similarly, the price of the modeled US BBB-rated portfolio with the same residual maturity as the UST portfolio is

$$
P_{\mathrm{BBB}}=\sum_{i=1}^{T} \frac{C_{\mathrm{BBB}}}{\left(1+y_{\mathrm{BBB}}\right)^{k}}+\frac{F_{\mathrm{BBB}}}{\left(1+y_{\mathrm{BBB}}\right)^{T}},
$$

where $C_{\mathrm{BBB}}$ stands for average annual coupon, $F_{\mathrm{BBB}}$ stands for face value of a principal payment, and $y_{B B B}$ is the blended yield. The yields and coupons are given by the respective indices S200YL and S200CP. The face value is again US\$ 1,000 million. Capital gains of US BBB-rated bond portfolio can be written as

$$
C G_{\mathrm{BBB}}(t, H)=P_{\mathrm{BBB}}(t+H)-P_{\mathrm{BBB}}(t),
$$

with symmetric notation. Equations (2) and (4) can be used to construct a time series of capital gains $C G_{\mathrm{UST}}$ and $C G_{\mathrm{BBB}}$, which can be used to calculate the sensitivity of the relatively risky US BBB-rated bond portfolio capital gains to the capital gains of the risk-free UST bond portfolio. Following the earlier definition, the sensitivity $S_{\mathrm{BBB} / \mathrm{UST}}\left(t_{2}, t_{1}, \mathrm{H}\right)$ is the ratio of the capital gain of the corporate bond portfolio to the capital gain of the UST portfolio over a period $\left(t_{1}, t_{2}\right)$.

$$
\begin{aligned}
S_{\mathrm{BBB} / \mathrm{UST}}\left(t_{2}, t_{1}, H\right) & =\frac{C G\left(t_{2}, H\right)_{\mathrm{BBB}}-C G\left(t_{1}, H\right)_{\mathrm{BBB}}}{C G\left(t_{2}, H\right)_{\mathrm{UST}}-C G\left(t_{1}, H\right)_{\mathrm{UST}}} \\
& =\frac{\Delta C G\left(t_{2}, t_{1}, H\right)_{\mathrm{BBB}}}{\Delta C G\left(t_{2}, t_{1}, H\right)_{\mathrm{UST}}} .
\end{aligned}
$$

The horizon $H$ is moved forward by the number of days equal to $t_{2}-t_{1}$. To make the capital gain-wise sensitivity more representative, we calibrate the rolling window of length $H$ so that it captures the more pronounced moves in the capital gains time series of the modeled UST portfolio. An infinitesimal or even zero change in the capital gain of the UST portfolio amplifies the computational uncertainty for the ratio and a zero denominator may render it useless.

It is important to remark that although the measure practically uses bond face values and yields, it can also provide intuition for the dynamics of interest rates. Interest rates and the yields of UST move towards the same direction, so an increase in the Fed rate pushes the yield curve for UST bonds upwards. Changes in nominal rates (e.g., due to inflation, fiscal, or monetary policy) are matched by changes in the yield curve, with a direct effect on the credit spread 
between government and corporate bonds. Our method fits well with a strategy that hedges interest rate risk by shorting the UST portfolio and essentially assesses the profitability of a long position in US BBB-rated bonds coupled with a short position in government bonds. This intuition is useful for connecting our findings with the wider literature that explicitly uses interest rates and spreads.

\section{Empirical Results}

3.1. Present Values and Capital Gains of Bond Portfolios. Figure 1 presents the historical time series of the yields and coupons of the UST bonds and US BBB-rated bonds.

For UST bonds, the average coupon almost always exceeds the corresponding yield rate, with the exception of the twoyear-long period preceding the global financial crisis, namely, from the second half of 2005 until the end of the first half of 2007. To a lesser extent, the same holds for corporate bonds apart from the financial crisis period: mid-2008 to mid-2010. Notably, the surge in the yields of corporate bonds during the financial crisis is well above the coupon curve, signifying a period where these assets were traded at a great discount. This change in trend will become apparent later on.

We then proceed to discount the future cash flows for the two portfolios based on the yield and coupon data. The resulting bond prices (see Figure 2) demonstrate a similar pattern between mid-2003 and the outbreak of the financial crisis in mid-2007. Since the second half of 2007 until the peak of the crisis, a large flight-to-quality event is observed, where the prices of safe assets increase and the prices of risky assets decrease [17]. In 2009, this flight-to-quality stops and the gap between the two curves vanishes. Notably, the ranges of the present values of the two portfolios differ considerably. The range relative to the UST portfolio (US\$ 150 million) is narrower than the respective range of the present values of the US BBB-rated bond portfolio (US\$ 250 million).

Capital gains for each portfolio can be directly calculated from our earlier definition. While the interpretation for the separate UST and US BBB-rated bond portfolios is straightforward, we also discuss the capital gains of a US BBB-rated portfolio hedged by taking a short position in UST bonds. In this case,

$$
C G_{\text {hedged }}=\mathrm{CG}_{\mathrm{BBB}}-\mathrm{CG}_{\mathrm{UST}} \text {. }
$$

Figure 3 represents the time behavior of yearly changes in present value for the US BBB-rated bond portfolio, the risk-free UST portfolio, and a portfolio of US BBB-rated bonds hedged by shorting the respective UST portfolio. Each point represents the changes in present value having taken place in the preceding year. Between July 2007 and December 2010, the period of the global financial crisis and its immediate aftermath, the annual capital gains of the BBBrated bond portfolio and UST bond portfolio move in opposite directions. Hence, the interest rate hedging of US BBB-rated debt with the short UST positions does not compensate the negative impacts, when such compensation is most needed.
3.2. Capital Gain-Wise Interest Rate Sensitivity of US BBBRated Debt. The main intuition lies in the interpretation of capital gains sensitivity across the portfolios we consider, namely, the US BBB-rated and UST portfolios and the hedged portfolio. Instead of using average sensitivity over the entire sample, we examine the behavior of sensitivity within much shorter time intervals determined by local extrema. Local minima and maxima are treated as turning points which separate upward and downward tendencies in capital gains dynamics.

The tracking of large movements in UST capital gains reduces the uncertainty in the denominator of equation (5) and hence increases the precision of sensitivity measurements. The extrema are identified in the time series of the UST portfolio, as in [18]. This leads to 51 sufficiently large and distinct movements, both upwards and downwards, which define the intervals we use and are split into three groups according to the time of occurrence. 18 movements took place during the precrisis period (March 2002-May 2007), 8 movements belong to the crisis period (May 2007-October 2010), and 25 movements happened during the postcrisis period (October 2010-August 2016). Sensitivity is calculated separately for each of the intervals. The resulting pattern can be seen in Figure 4, along with average sensitivity for each of the three phases.

The bold line depicts the two different regimes. During normal economic conditions, the average sensitivity is positive, while during the crisis, it is negative and amplified. We clearly observe the time-varying behavior of capital gains sensitivity over each phase, similar to $[9,11]$. The plot shows that sensitivity is mostly positive before 2007 and after 2011, while it turns negative between that time interval. This implies a regime change during and slightly after the period of the financial crisis. From 2001 till 2007, the sensitivity remains positive, from 2007 till 2011, it turns negative, and from 2011 till 2016, it reverts back to positive ground. To properly calculate the sign and value of sensitivity in a way that is not affected by time variation, we take the product of capital gains and duration (time interval) over which the sensitivity point estimates are given. This yields a weighted sum of capital gains for each portfolio, where the weight is the fraction of time over which sensitivity (capital gains) was calculated. The average period sensitivity is, thus, the ratio of the weighted sum of capital gains for the US BBB-rated portfolio divided by the UST equivalent. In comparison, spread-to-rate sensitivity typically takes daily values which are averaged over a longer period, whereas our metric focuses on start and end points.

As discussed earlier, the definition of our measure can be interpreted as a gauge of hedging success when a long position in the BBB-rated portfolio is balanced by a short position in the UST portfolio. In terms of cash flows, this can be seen as either a permanent position or an interest rate swap that pays a fixed rate to receive a floating rate equal to that of the corporate bond portfolio. It becomes apparent that all the gains from the short position in UST during the precrisis period are wiped away during the crisis downturn and recovery. As such, an all-weather hedge or its equivalent in the form of a swap is inefficient. 


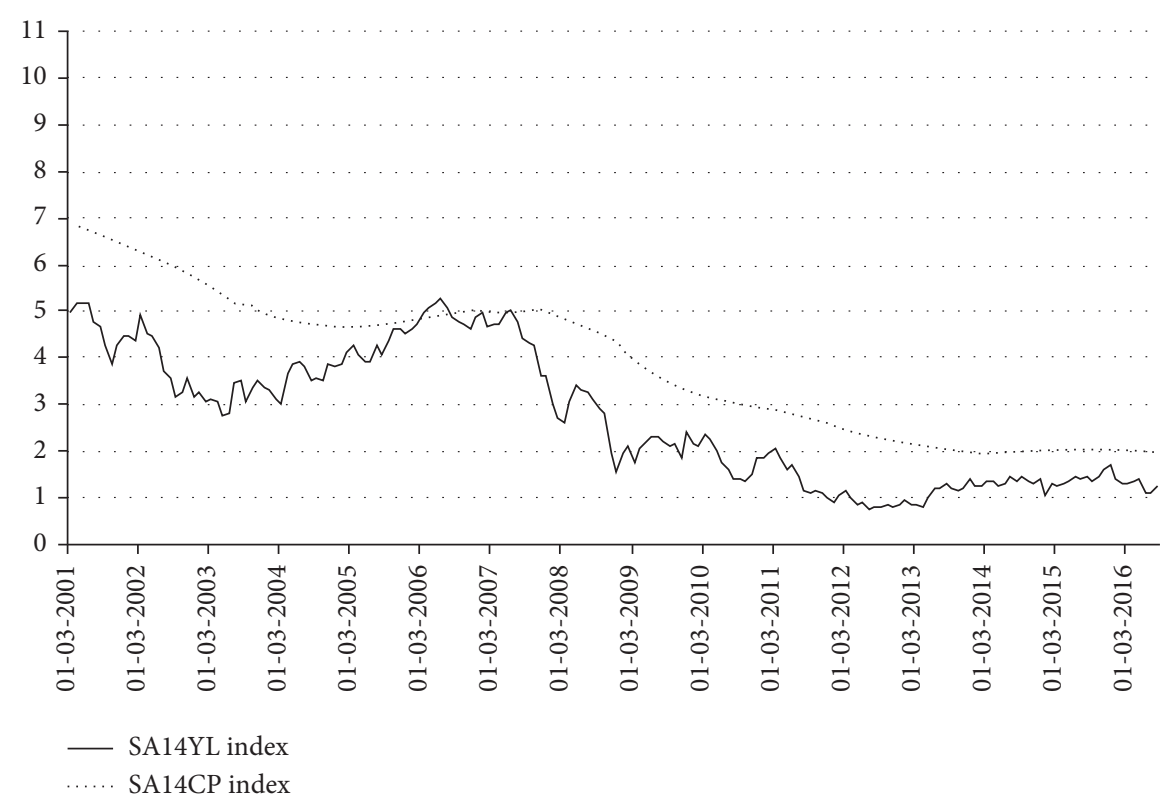

(a)

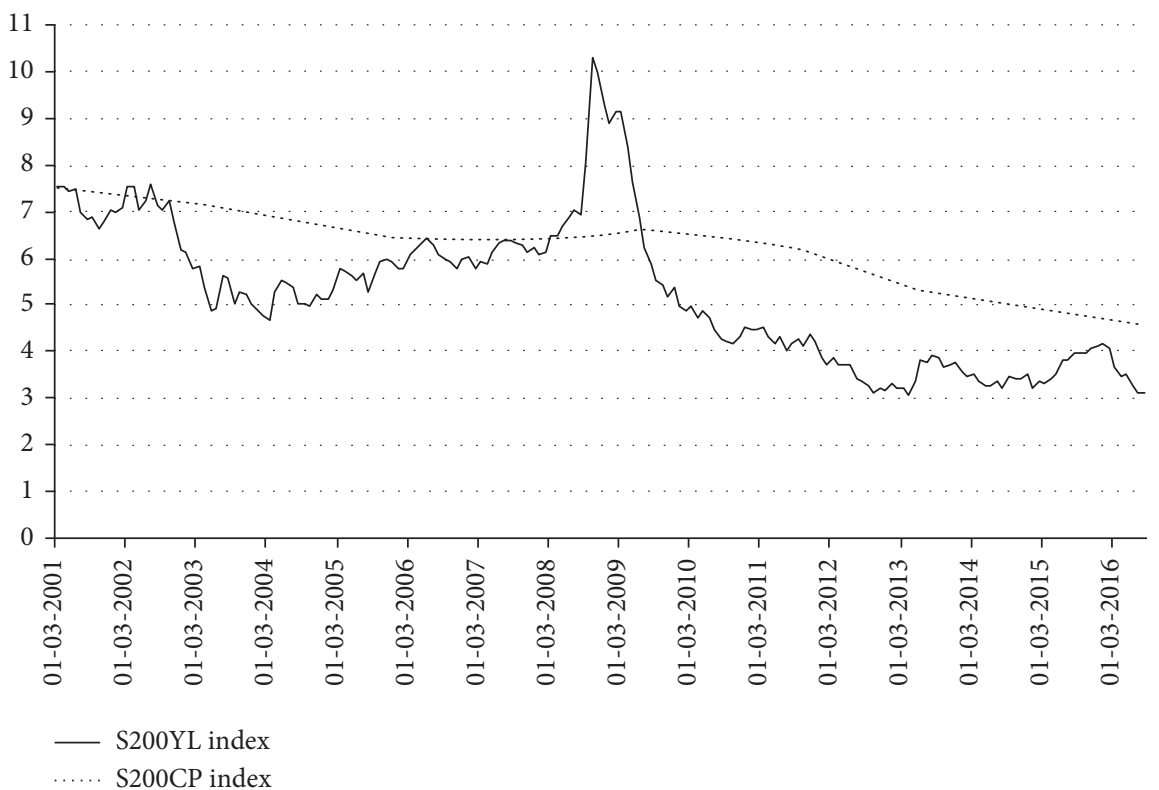

(b)

FIgURE 1: Yields and average coupons for the US BBB-rated (a) and UST bonds (b), \%.

Section 4 confirms our empirical observation of capital gain-wise interest rate sensitivity regime changes by application of Markov-switching model.

\section{Markov-Switching Modeling and Regime Changes}

Up to this point, our empirical findings point towards a structural break in the time series we use. This underlines a functional discrepancy best represented by the contradiction between the Merton [4] model, implying a permanently negative relationship between credit spreads and interest rates, and the Kamin and von Kleist [6] approach, which does not identify such a relationship for a certain period. Given the direct correspondence between interest rates and the yields of government bonds, it is straightforward to connect the intuition of the previous section to the two regimes. To test the hypothesis of two alternating states, one where the Merton model is valid and capital gains sensitivity (and conversely the relationship between credit spreads and interest rates) is negative and one where capital gains sensitivity is close to zero (and the relationship between interest rates and credit spreads is roughly one-to-one), as in $[6,7]$, we estimate a simple Markov-switching model with two regimes using the time series of sensitivity and capital gains of the hedged bond portfolio. The figures in the 


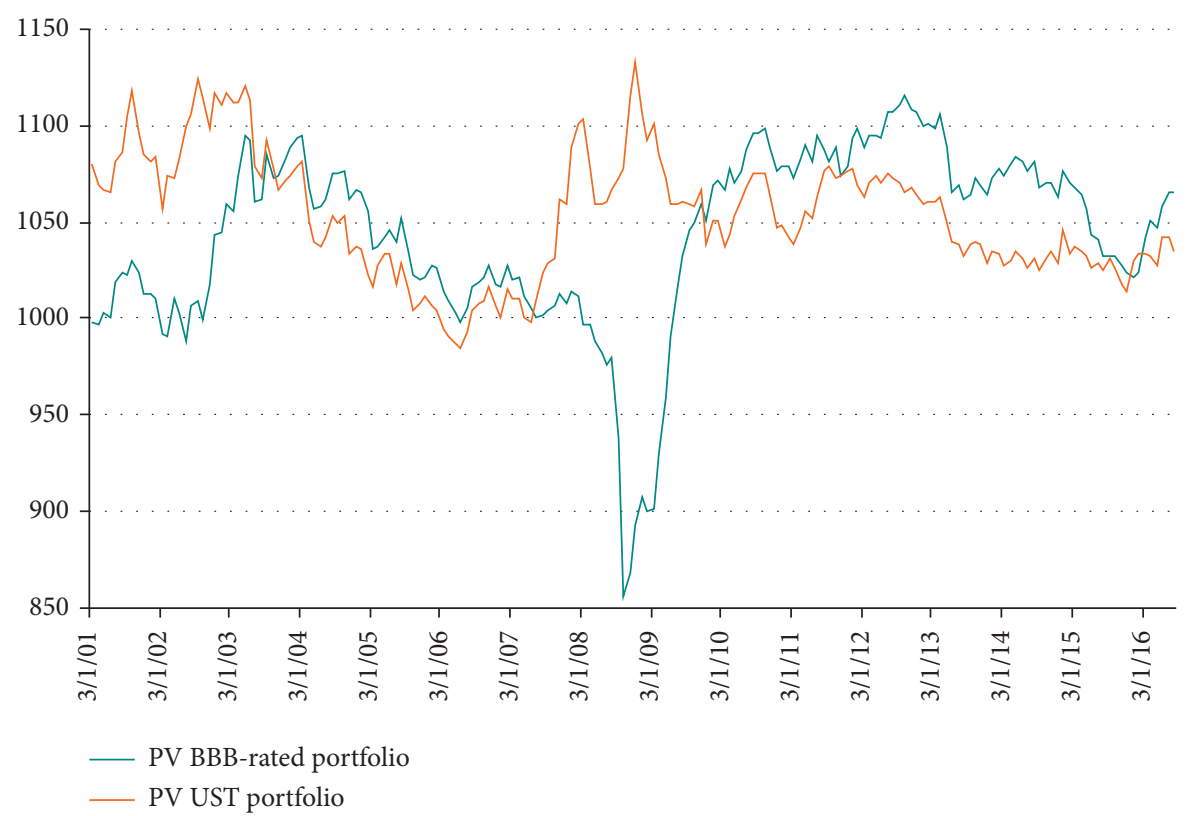

FIgURE 2: Present values of portfolios: US BBB-rated bonds vs. UST.

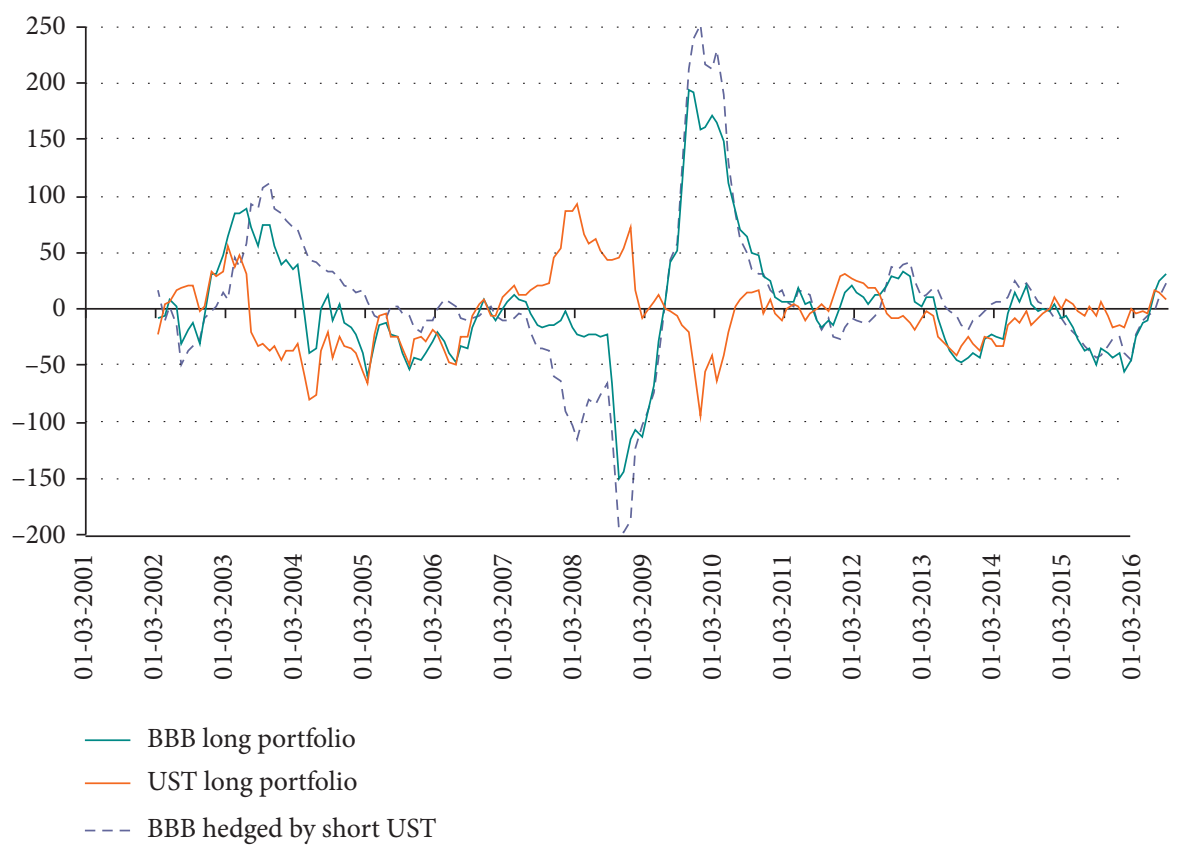

FIGURE 3: Yearly capital gains for the US BBB-rated, UST, and hedged portfolios.

previous section show a possible regime switch in the period averages, but we also examine whether the two different regimes may also have distinct volatilities.

From the vast literature on Markov-switching and regime-switching models, we select a set of simple applications in line with the arguments detailed in $[19,20]$. For wider applications on asset pricing, portfolio optimization, and stochastic volatility, [21] contains a comprehensive literature review. We employ a simple two-state dynamic regression Markov-switching model (DRMS), which is more suitable to the monthly frequency of our data. A DRMS specification allows the probabilities to change instantaneously across states, since the realization of each state $s_{\mathrm{t}}$ does not depend on $s_{t-1}$ but is drawn from a discrete probability distribution. On the other hand, an autoregressive (AR) specification where $s_{\mathrm{t}}$ follows a Markov process, thus allowing the transition probabilities to follow an AR process, would introduce autocorrelation in states since $s_{\mathrm{t}}$ would depend on $s_{t-1}$. This is an unwelcome feature for our model for many reasons. Markov-switching AR (MSAR) models are better suited for quarterly or annual data, and the introduction of lagged states multiplies the states. In our case, due to 


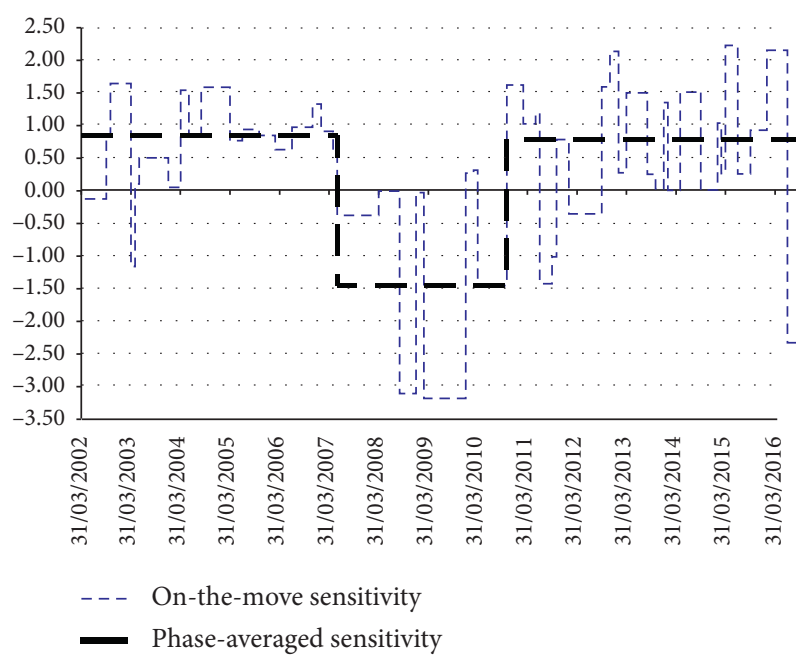

FIGURE 4: Phase-averaged sensitivity of US BBB-rated bonds, 2002-2016.

autoregression, there would be four possible regimes instead of two, without providing any additional intuition. Also, an MSAR specification would not allow the probabilities to adjust quickly enough to changes in states. Regardless, preliminary estimations of an AR specification yielded very similar results, so we base our discussion on the DRMS models only.

A general specification of the DRMS model that captures all the subcases we consider is

$$
Y_{t}=\mu L_{\mathrm{st}}+\varepsilon_{\mathrm{st}}, \quad \varepsilon_{\mathrm{st}} \sim N\left(0, \sigma_{\mathrm{st}}^{2}\right),
$$

where $t$ denotes time, $Y$ is the time series (sensitivity or portfolio capital gains), $s$ denotes the state and is set to 1 or $2, \mu$ and $\sigma$ denote the state dependent model parameters of the mean (intercept) and the standard deviation, and innovations $\varepsilon$ are independent and identically distributed, following a normal distribution with state-dependent variance. We consider two variations: one where the means are state dependent and one where not only the means but also the variances are state-dependent too. The notation can be simplified in the case where only the means are allowed to switch across states to $\sigma^{2}{ }_{s}=\sigma^{2}$ (constant across both time and states) and remains as above in the case where both means and variances are state dependent ( $\mu_{\mathrm{s}}$ and $\sigma_{s}^{2}$ omitting $t$ for brevity). This leads to four different estimations, two for sensitivity, and two for capital gains. The Akaike, Hannan-Quinn, and Schwarz information criteria show that the simplest model with no lagged terms is the most suitable one for all cases, for both sensitivity and capital gains; hence, we do not introduce lags.

4.1. Regime Switching in Sensitivity. Table 1 reports the results for capital gains sensitivity when only the means are state dependent, under a model specified as $Y_{\mathrm{t}}=\mu_{\mathrm{st}}+\varepsilon_{\mathrm{t}}$, $\varepsilon_{\mathrm{t}} \sim \mathrm{N}\left(0, \sigma^{2}\right)$ for states $s=1,2$. State 1 corresponds to the Merton model, where $s$ is negative, and state 2 corresponds to the Kamin and von Kleist approach, where $s$ is near zero and positive. The estimation verifies our earlier observations, since $\mu_{1,2}$ are both statistically significant, with a negative value of -2.41 and a positive value of 0.70 , respectively. The probabilities for each state are 0.838 and 0.968 , respectively, which show very high persistence for both regimes.

The transition probabilities from state 1 (2) to state 2 (1) are $0.162(0.032)$, which show a very low rate of change (see Table 2). This indicates very clear breaks in the time series and high certainty over which state occurs, which is a direct outcome of the DRMS specification.

Figure 5 shows the transition probabilities compared to the evolution of sensitivity during our period.

Figure 5 evidences a dominance of the second state up until 2009, with a brief exception around 2003 and a dominance of the first state between 2009 and 2011. State 1 briefly reappears at the end of 2012. During the 2009-2012 period, any changes from state 1 to state 2 are instantaneous, meaning that the sensitivity reverts immediately back to its initial regime. After 2012, the second state is always present.

These findings show that sensitivity and credit spreads vary over time, with two distinct regimes appearing, which correspond to two different theoretical approaches on the relationship between credit spreads and interest rates. During crises, credit spreads and interest rates move in opposite directions following the Merton pattern of negative sensitivity. During normal periods, any changes in interest rates (risk-free yields) pass on nearly completely to the yields of corporate bonds, which implies stable credit spreads and the Kamin and von Kleist pattern.

When regime changes are allowed in both the mean and the variance, the parameters and transition probabilities are generally similar (Table 3 ). The model specification follows equation (7). However, the plot of the transition probabilities over the time series reveals that only state 2 manifests throughout our entire period, i.e., there is not a switch from one pattern to the other and only the Kamin and von Kleist rationale is validated. The variance of state $1(0.90)$ is considerably higher than the variance of state $2(0.51)$ and slightly higher than the variance of the means-only regimeswitching model (0.79). Moreover, the means of the two states are closer compared to the previous case. One possible explanation is that the higher variance combined with the higher mean of state 1 makes the first state redundant despite its high persistency. The mean estimate of -1.34 has a standard deviation of 0.2 , which coupled with the standard deviation of the state brings it well within the range of state 2 . We therefore conjecture that this similarity causes the model not to discriminate between states.

4.2. Regime Switching in the US BBB Portfolio Hedged by Shorting UST. We can now proceed to the capital gains of the hedged synthetic portfolio where UST bonds are shorted. The capital gains of the hedged portfolio are calculated as follows. First, the present values of the UST and BBB portfolios are calculated using equations (1) and (3), setting $T=5$ and FV $=1.000$. Since the S200YL, S200CP, SA14YL, and SA14CP indices are monthly, we calculate monthly 
TABLE 1: Markov-switching regression in means only for sensitivity.

\begin{tabular}{lccccc}
\hline Parameter & Estimate & $\begin{array}{c}\text { St. } \\
\text { error }\end{array}$ & $z$ & $P>|z|$ & $\begin{array}{c}95 \% \text { confidence } \\
\text { interval }\end{array}$ \\
\hline$\mu_{1}$ & -2.408 & 0.163 & -14.74 & 0.000 & $(-2.729,-2.088)$ \\
$\mu_{2}$ & 0.701 & 0.662 & 10.60 & 0.000 & $(0.571,0.831)$ \\
$\sigma$ & 0.791 & 0.044 & & & $(0.709,0.882)$ \\
p11 & 0.838 & 0.073 & & & $(0.644,0.937)$ \\
p21 & 0.033 & 0.015 & & & $(0.014,0.077)$ \\
\hline
\end{tabular}

The Merton case corresponds to state 1; the Kamin and von Kleist case corresponds to state 2 .

TABle 2: Transition probabilities between state 1 and state 2 for all models.

Regime switch in means only

Sensitivity

BBB hedged by short UST

State from/to State 1 State 2 State from/to State 1 State 2

$\begin{array}{llllll}\text { State } 1 & 0.838 & 0.162 & \text { State } 1 & 0.987 & 0.013\end{array}$

$\begin{array}{llllll}\text { State } 2 & 0.033 & 0.967 & \text { State } 2 & 0.104 & 0.897\end{array}$

Sensitivity Regime switch in means and standard deviations

State from/to State 1 State 2 State from/to State 1 State 2

$\begin{array}{llllll}\text { State } 1 & 0.837 & 0.163 & \text { State } 1 & 0.987 & 0.013\end{array}$

$\begin{array}{llllll}\text { State } 2 & 0.111 & 0.889 & \text { State } 2 & 0.087 & 0.913\end{array}$

The Merton case corresponds to state 1; the Kamin and von Kleist case corresponds to state 2 .

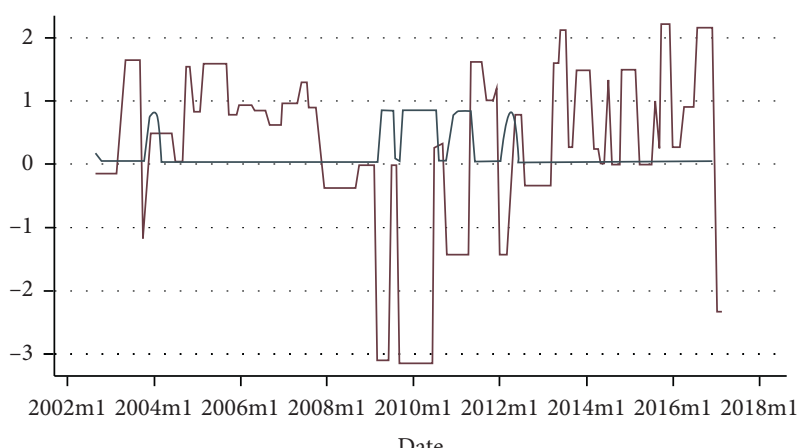

- State 1, one-step probabilities
_ Sensitivity of BBB bonds

FIGURE 5: Regime change in means only: state plot for the sensitivity time series. Probability with respect to state 1 .

TABLE 3: Markov-switching regression in means and standard deviations for sensitivity.

\begin{tabular}{lccccc}
\hline Parameter & Estimate & $\begin{array}{c}\text { St. } \\
\text { error }\end{array}$ & $Z$ & $P>|z|$ & $\begin{array}{c}95 \% \text { confidence } \\
\text { interval }\end{array}$ \\
\hline$\mu_{1}$ & -1.345 & 0.201 & -6.68 & 0.000 & $(-1.739,-0.951)$ \\
$\mu_{2}$ & 0.842 & 0.142 & 5.94 & 0.000 & $(0.564,1.119)$ \\
$\sigma_{1}$ & 0.909 & 0.097 & & & $(0.739,1.119)$ \\
$\sigma_{2}$ & 0.516 & 0.042 & & & $(0.439,0.606)$ \\
p11 & 0.837 & 0.048 & & & $(0.720,0.911)$ \\
p21 & 0.111 & 0.032 & & & $(0.629,0.190)$ \\
\hline
\end{tabular}

The Merton case corresponds to state 1; the Kamin and von Kleist case corresponds to state 2 . present values for the two portfolios. We then calculate the difference between the present value of month $t$ and the present value of month $t-12$, or the difference over an annual interval. The capital gain of the hedged portfolio is, therefore, the capital gain of the long position on BBB corporate bonds minus the capital gain of the short position on US Treasury bonds. The generated capital gains span from March 2002 till September 2016. More succinctly, formula (6) can be written as follows for $H=12$ months and $P$ the present value (price) of a portfolio:

$$
\begin{aligned}
C G_{\text {hedged }}(t, H)= & C G_{\mathrm{BBB}}-C G_{\mathrm{BBB}}=P_{\mathrm{BBB}}(t+H)-P_{\mathrm{BBB}}(t) \\
& -P_{\mathrm{BBB}}(t+H)-P_{\mathrm{BBB}}(t) .
\end{aligned}
$$

The $\mathrm{CG}_{\text {hedged }}$ series is used to estimate different Markovswitching models, whose results are reported in Tables 4 and 5. We follow the same approach with sensitivity and employ a DRMS model with no lags. The pattern is similar to that of sensitivity. When the variance is common for the two states and only the means change, there are two major regime switches (Figure 6).

One of the changes, which lasts longer, takes place between 2010 and 2011, which corresponds to the financial crisis. The other change takes place in 2004, is slightly less pronounced, and coincides with a minimum in the time series of UST capital gains. It is worth noting that this minimum of UST capital gains occurs within the one-yearlong time interval (June 2003-June 2004), when the federal fund target rate remains at its local minimum value of $1 \%$. The transition probabilities are again very persistent, as shown in Table 4 . State 1 has a probability of 0.99 , state 2 has a probability of 0.896 , and the probability to move from state 1 (2) to state $2(1)$ is $0.01(0.104)$. Similarly, the mean of the first state $(-11.39)$ is negative and corresponds to the Merton case, while the mean of the second state (134.79) is positive and corresponds to the Kamin and von Kleist case (see Table 4).

In its turn, Table 5 demonstrates that when switches in both the means and the variances are allowed, the result is similar to the previous section. The means change marginally, but the much higher variance of one state (69.01) causes it to dominate over the second state, which has a variance similar to that of the means-only switch (42.97).

Figure 7 shows how the probability of a state to be realized remains at $2 \%$ or equivalently how the other state persists and there are no switches during the period. On the other hand, Figure 6 clearly shows two different states when the means are state dependent but the variance is not. This makes state-dependent variances inappropriate for our purposes. Allowing for a change in variances leads to much higher estimates, which cause one state to cover a much wider range of potential values. This makes the model uninformative and unable to pick the differences that interest the paper. As a result, we base our results in the cases where the variance across states is common and the regime switch is in the mean. 
TABLE 4: Markov-switching regression in means only for the US BBB portfolio hedged by shorting UST bonds.

\begin{tabular}{lccccc}
\hline Parameter & Estimate & $\begin{array}{c}\text { St. } \\
\text { error }\end{array}$ & $z$ & $P>|z|$ & $\begin{array}{c}95 \% \text { confidence } \\
\text { interval }\end{array}$ \\
\hline$\mu_{1}$ & -11.397 & 4.038 & -2.82 & 0.005 & $(-19.312,-3.483)$ \\
$\mu_{2}$ & 134.794 & 14.953 & 9.01 & 0.000 & $(105.486,164.102)$ \\
$\sigma$ & 47.034 & 2.556 & & & $(42.281,52.321)$ \\
p11 & 0.988 & 0.009 & & & $(0.951,0.997)$ \\
p21 & 0.104 & 0.068 & & & $(0.027,0.326)$ \\
\hline
\end{tabular}

State 1 is the Merton case; state 2 is the Kamin and von Kleist case.

TABLE 5: Markov switching regression in means and standard deviations for the US BBB portfolio hedged by shorting UST.

\begin{tabular}{lccccc}
\hline Parameter & Estimate & $\begin{array}{c}\text { St. } \\
\text { error }\end{array}$ & $\mathrm{z}$ & $P>|z|$ & $\begin{array}{c}95 \% \text { confidence } \\
\text { interval }\end{array}$ \\
\hline$\mu_{1}$ & -13.258 & 3.812 & -3.47 & 0.001 & $(-20.745,-5.771)$ \\
$\mu_{2}$ & 119.439 & 18.024 & 6.63 & 0.000 & $(84.112,154.766)$ \\
$\sigma_{1}$ & 42.970 & 2.556 & & & $(38.241,48.283)$ \\
$\sigma_{2}$ & 69.012 & 9.987 & & & $(51.969,91.644)$ \\
p11 & 0.987 & 0.009 & & & $(0.949,0.997)$ \\
p21 & 0.087 & 0.057 & & & $(0.023,0.280)$ \\
\hline
\end{tabular}

Merton case: state 1; Kamin and von Kleist case: state 2.

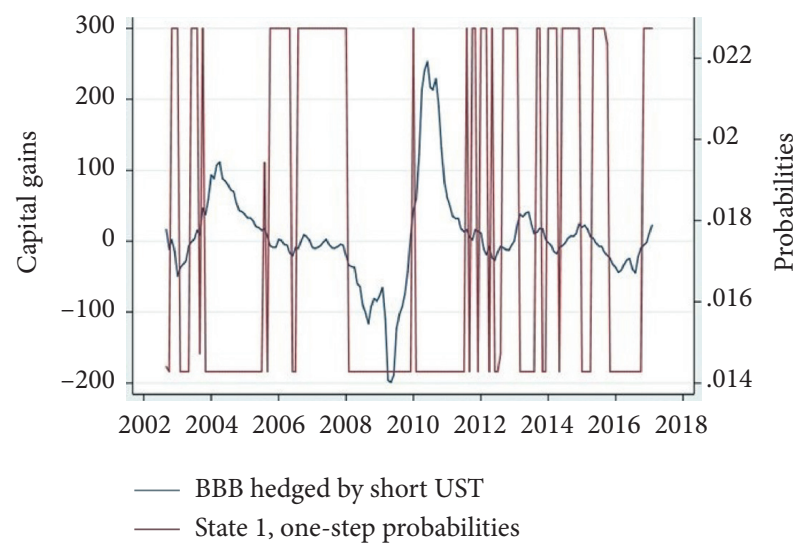

FIGURE 6: Regime change in means only: state plot for the capital gains hedged US BBB portfolio, 3/2002-9/2016.

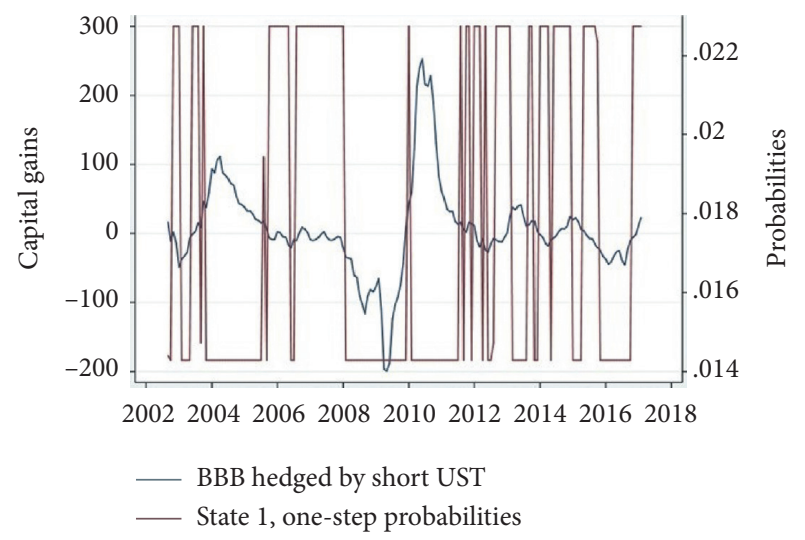

FIGURE 7: Regime change in means and standard deviations: state plot for the capital gains of the UST-hedged US BBB portfolio, 3/2002-9/2016.
It must be stressed that such effects can be identified only if averaging over a very long sample is avoided. The average sensitivity for the entire period is slightly below zero, meaning the strong negative sensitivity in the second period cancels out the low positive sensitivity in the first and third periods. This may lead to flawed or counterintuitive results, particularly if the effect of one regime is very strong or if strong effects in all regimes negate each other. It is even possible to conclude that there is no sensitivity relative to either yields or capital gains. This finding also provides an illustration on why long spread-to-rate sensitivity averages failed to capture the dynamics depicted by our measure.

\section{Discussion and Implications}

5.1. The Relationship between Credit Spreads, Interest Rates, and Yields. The estimation results provide sufficient evidence on the time variation in the relationship between credit spreads and yields or interest rates. They suggest a compromise between the pattern identified by Merton [4] of a negative relationship and the findings of Kamin and von Kleist [6] of no strong relationship between spreads and interest rates. We show that, on the contrary, the relationship is not constant and alternates between two phases, each of which corresponds to one of the two approaches. The Kamin and von Kleist intuition (state 2) appears in normal periods, while the Merton intuition (state 1) appears during distress times. During normal periods, changes in interest rates are fully passed on to the yields of BBB-rated bonds, leaving credit spreads unaffected. During crises, on the other hand, the increased uncertainty leads to a flight-to-quality from the riskier corporate bonds to the safe risk-free UST bonds, which pushes the respective yields to opposite directions. After the end of a crisis, the flight to quality stops and there is a reversion to the regime of the normal period. Our findings contradict literature that supports a constant relationship (e.g., [3]) both on the basis of constant sensitivity over time and on the effect of business cycles on credit spreads.

Capital gains of the hedged US BBB portfolio exhibit two regime changes which coincide with the two highest capital gains of the UST Long portfolio (see Figure 4 for a joint presentation). A potential answer to what triggers regime changes may lie in expectations on the risk-free rate as viewed through the Fed target rates. Between June 2003 and June 2004, the federal fund rate reached a minimum value of $1 \%$ (see Figure 8). At the same time, a maximum in UST capital gains was realized. A similar situation occurred in 2009, which coincides with another regime change.

The same discussion can be held in terms of default probabilities. In state 1 , changes in risk-free interest rates (yields) have a significant opposite effect on US BBB bond yields, while in state 2 , a change in risk-free interest rates is reflected by changes in US BBB bond yields of the same size and magnitude. During the precrisis period (state 2), the average capital gains sensitivity of US BBB-rated bonds is close to 1 , averaging at 0.84 , particularly between 2004 and 2007. Therefore, the response of US BBB bonds to changes in the yields of risk-free assets on a capital gains basis is slightly 


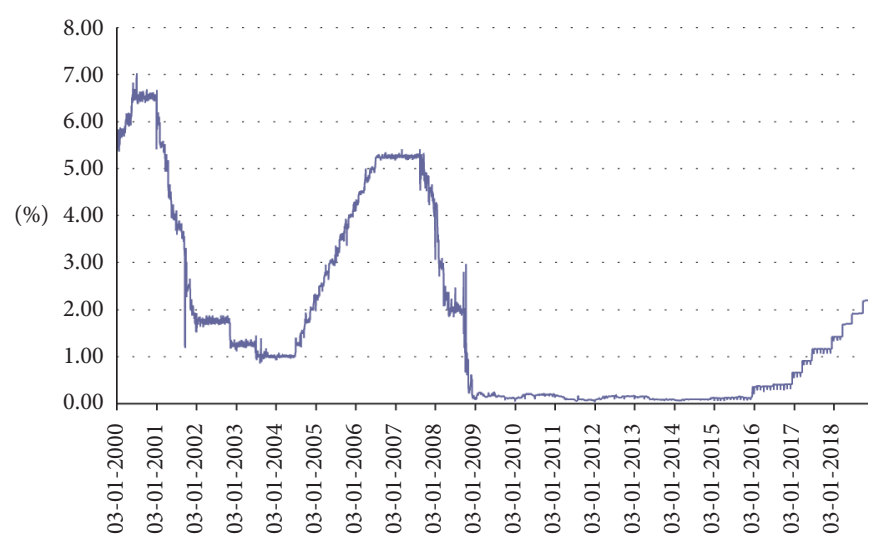

FIGURE 8: US federal fund effective rate.

lower than 1-to-1, and changes in the yield of risk-free assets passing on to the yield of corporate bonds are slightly reduced. According to [6], the probability of default is not affected by changes in the interest rate and hence a change in the latter does not result in a significant response. On the contrary, between 2007 and 2010 (state 1), sensitivity becomes much more volatile and dips in negative territory. The average sensitivity is clearly negative at a level of -1.47 , which signifies a negative and amplified response of credit spreads to changes in interest rates. According to [4], which is based on contingent claims, such a negative response implies that the probability of default of a debt issuer is affected by changes in the interest rate. The increase in credit spreads signifies a higher credit risk and probability of default.

This, in turn, is a signal for the creditworthiness of debt issuers. After 2010, the intuition of Kamin and von Kleist emerges again, with a positive average sensitivity of 0.78 .

Although the time span of our analysis ends in August 2016, there is an interesting period ahead with environments with prolonged low interest rates that had fostered risk-taking up to the coronavirus crisis. Such risk-taking scenario has been faced by advanced economies for some time and then, later, on the eve of the pandemic-fueled crisis, by some developing countries. As the impacts of the coronavirus crisis, from the point of view of the interestrate-based finance, are commensurate with those of the 2007-2008 global financial crisis, we consider the interest rate sensitivity of the BBB-rated nongovernmental US bonds during the coronavirus recession to be negative and amplified. It is so because the US Treasury yields are diminishing towards the all-time low, while the precoronavirus bubble in the BBB-rated debt outstanding makes the yields of the nongovernmental relatively risky BBBrated bonds climb. Thus, in accordance with our back-onthe-envelope estimates, our conclusions hold in this environment. However, thorough rigorous investigation of the low interest rates' influence and the impacts of coronavirus on the interest rate sensitivity is desirable and will be addressed in our further research. We also posit that during the initial recovery from the coronavirus crisis lows, the interest rate sensitivity will remain negative, this time because of the increase in UST treasury yields-due to the economic recovery-accompanied by the decrease in BBB-rated yields-due to improving business conjuncture and, hence, diminishing probabilities of default. The sensitivity plot around the coronavirus crisis will be qualitatively similar to that in Figure 4, but shifted, along the time scale to the right by roughly thirteen years, separating the two major crisis events.

5.2. Sensitivity and Hedging during the Business Cycle. The performance across diverse asset categories changes according to the phases of the business cycle [22, 23]. These phases are typically split into early-, mid-, and late-cycle phases and recession. During the mid- and late-cycle phases of economic expansion, interest rates tend to be higher to prevent the economy from overheating. During the recession and early-cycle phases, interest rates are kept lower to stimulate growth. Notably, these phases match those observed in the results for sensitivity and capital gains.

The first and third period of our sample, where spreads are generally constant, can be related to the mid and late phases of the business cycle, both empirically and theoretically. During those periods of normal to moderate economic growth, default probabilities are low and creditworthiness is only moderately by changes in the riskfree rate. During the second period, however, the inverse relationship can be related to the downside of the business cycle, where a recession (crisis) and the first stage of recovery have taken place. The observed flight-to-quality puts pressure on the prices of UST bonds, which are coupled by a central bank trying to stimulate the economy by reducing interest rates. Either of these factors, or their joint occurrence, pushes the yields of the risk-free assets upwards. Figure 9 demonstrates these points along with the observed yields of US BBB-rated securities vs. UST yields. The divergence between the two yield time series matches the behavior of credit spread with relation to the risk-free interest rate and the phase of the business cycle.

At the same time, the deteriorating economic conditions, low business performance, and increased uncertainty make corporate debt riskier, which pushes US BBB-rated yields upwards. Thus, companies face more difficulties in servicing existing debt and issuing new one at an acceptable rate. 


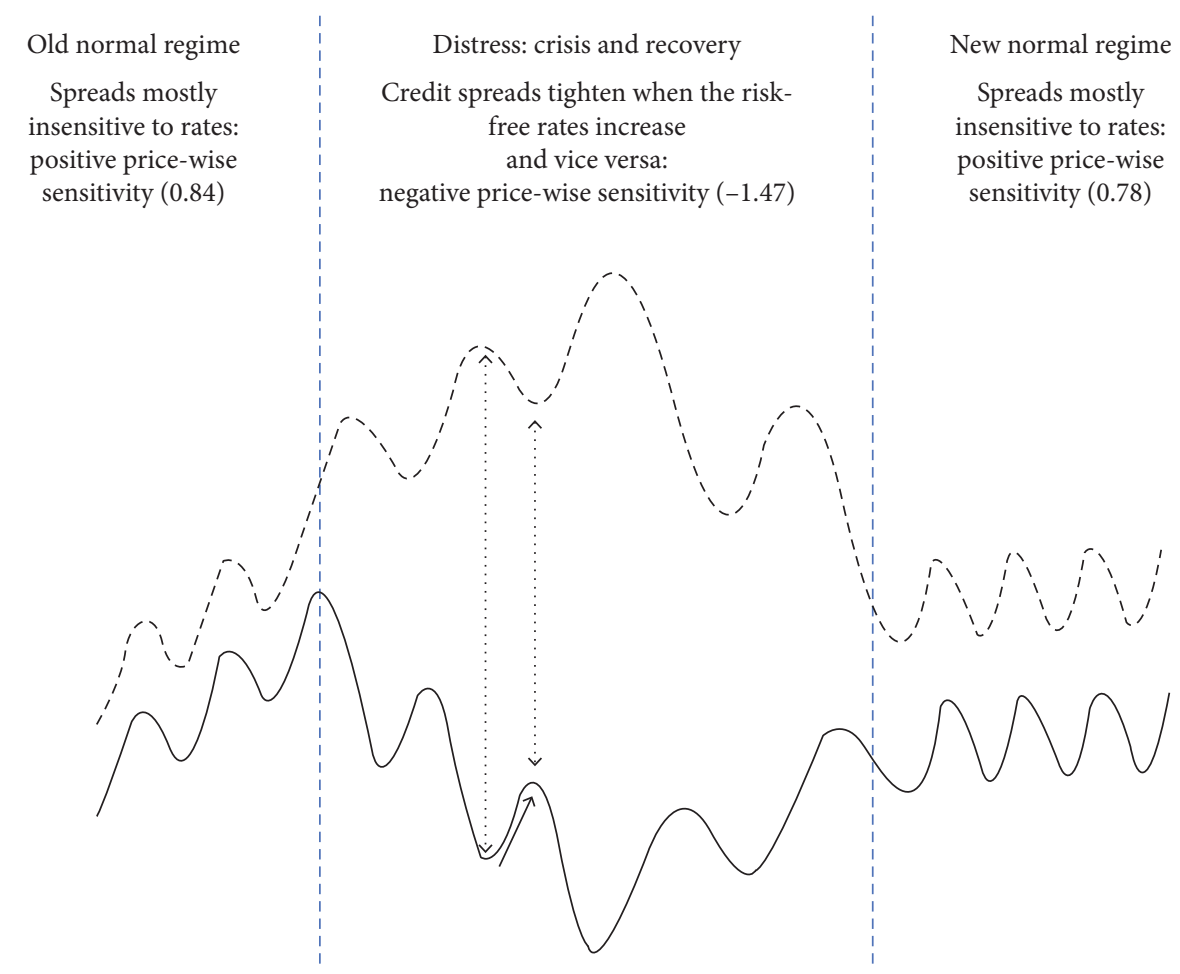

Risk-free rate

- - - Corporate yield

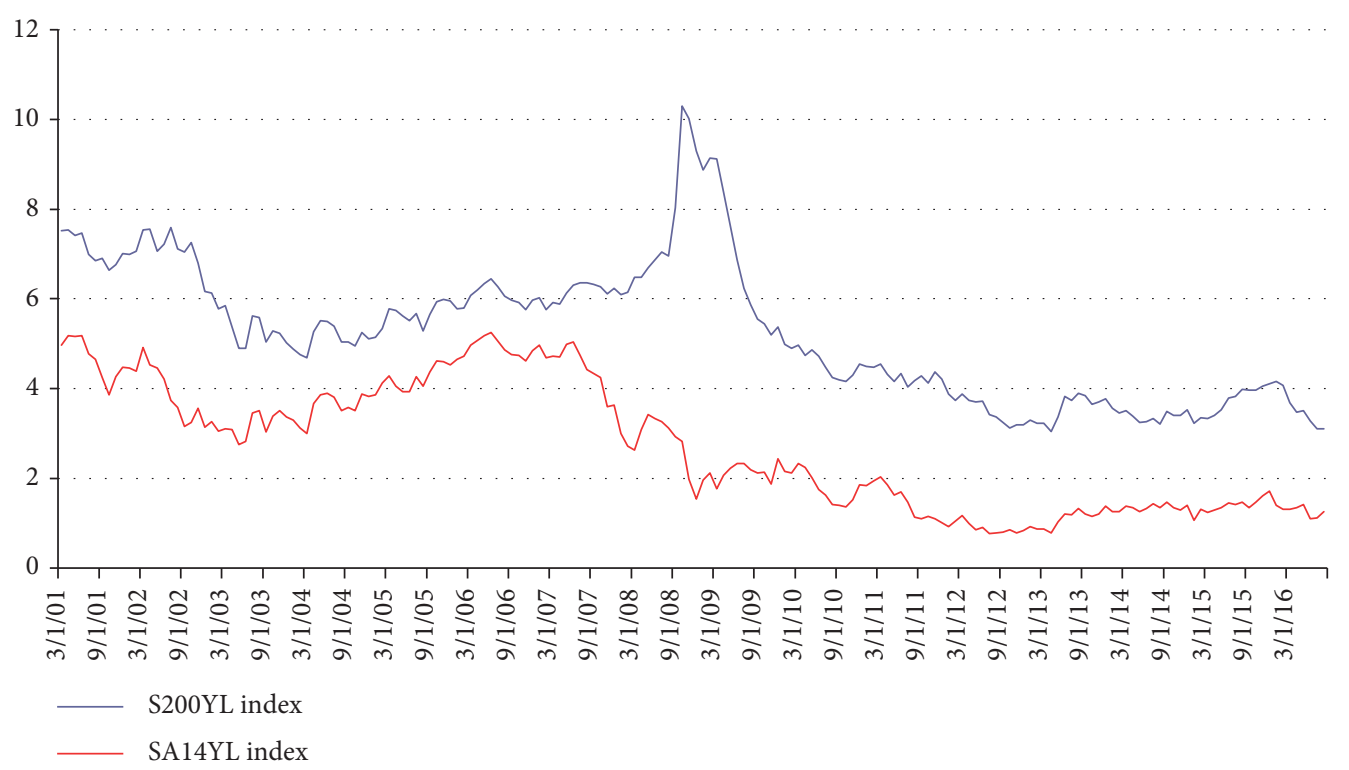

(b)

FIGURE 9: Spread-to-risk-free rate dynamics compared to observed yields. (a) Negative spread-to-rate sensitivity in distress compared to null sensitivity in "normal" times. (b) US BBB-rated (blue) and UST (red) bond yields.

Prices of corporate bonds move downwards and prices of government bonds move upwards. The movement from the second to the third period of our sample can be seen as the return to a "normal" state after an increase in interest rates from the central bank. Tighter monetary policy, coupled with an improvement of economic conditions, reduces the premia of corporate bonds since the yields of risk-free assets increase and default risk decreases. Capital losses are observed in UST portfolios while positive capital gains occur in corporate bond portfolios. The capital gains sensitivity of the US BBB-rated bonds during the recovery phase changes from negative to slightly positive. 
Our findings for the downward phase of the business cycle agree and expand on [3] but contradict their conclusions on the upward phase. They find both a constant relationship and no connection of their results to the business cycle. While we agree with a negative relationship between spreads and interest rates during the recession and early-cycle phases, we interpret the periods of economic expansion described in [3] as periods of sharp recovery from recession. We present evidence that under the normal regime of the mid-cycle and the late-cycle expansion, the negative relation between interest rates and credit spreads turns to insensitivity.

Under these circumstances, the dilemma of an investor in US BBB-rated bonds is a choice between a short position in UST bonds or, equivalently, an interest rate swap that receives a floating rate for a fixed rate. Our findings suggest that such a hedge is meaningful and profitable in the upward section of the business cycle, where spreads are relatively stable. If this position, however, is maintained during a recession or an early recovery stage, any profits will likely be eliminated swiftly, as suggested by our results [14]. In the downward part of the business cycle, an interest rate swap that receives a fixed rate for a floating rate would be more beneficial. Hedging, therefore, must be dynamic and include at least some degree of rebalancing as the business cycle progresses. As a result, we are able to show that a business cycle approach to interest rate hedging can add value as part of intermediate-term hedge strategies.

\section{Conclusion}

To study the comparative dynamics of US BBB-rated debt and UST bonds, we propose a comprehensive measure of sensitivity based on capital gains of the representative portfolios. The approach puts direct emphasis on profits or losses incurred by a portfolio due to changes in the underlying yields. While compared to assessing spreadto-rate sensitivity metrics, the capital gains measure reveals itself as a more suitable for the long-run investment perspective as this measure, by construction, is primarily focused on the profits or losses of bond portfolio on a year-on-year basis.

We reconcile two opposing strings of literature that assume a constant relationship between credit spreads of US BBB-rated bonds and the yields of risk-free UST, by showing that the relationship is not permanent but changes over time between two different regimes. The first regime corresponds to periods of high and moderate growth in the business cycle, during which credit spreads have little to no reaction to changes in interest rates and risk-free yields [6]. The second regime corresponds to periods of recession and sharp recovery from it, when credit spreads and interest rates move in opposite directions with amplified effect [4]. Our proposed capital gain-based metric is able to shed light on the dynamics of spreads and yields and explain a long-standing theoretical contradiction.

Apart from the theoretical contribution, our findings also have practical value for portfolio management and policy regulation. A sensible hedging strategy for bond portfolio would be to hold a long position in government bonds and a short position in risk-free bonds. Note that holding a short position in UST in such a synthetic portfolio is largely equivalent to a fixed-for-floating interest rate swap. However, under time-varying sensitivity, such a position is economically inefficient since losses in an economic downturn may be so severe that they may cancel out the gains obtained in normal times. Therefore, for long-term investments, dynamic positions and a proper reassessment of fundamentals are crucial. A portfolio investor that considers the phase of the economic cycle would not always rely on shorting UST as a hedge strategy, but would alter, or even reverse crossing a crisis, his exposure to risk-free UST instruments along the business cycle.

The implications for policy makers and portfolio investors alike lie in the proper timing of trends. A policy maker, on the other hand, should expect that, other positive effects notwithstanding, a reduction in interest rates during a recession may put additional pressure on corporate yields during a time of low economic performance and perceived high default risk. Our remarks contribute to the ongoing discussion of exposure to credit risk and risk assessment under the Basel III capital accord, namely, Pillar II methodologies.

\section{Data Availability}

The data used to support the findings of this study are available from the corresponding author upon request.

\section{Conflicts of Interest}

The authors declare that they have no conflicts of interest.

\section{Acknowledgments}

This research was supported by IPL (Instituto Politécnico de Lisboa) and by FCT, I.P., the Portuguese national funding agency for science, research and technology, under the project UIDB/04521/2020.

\section{References}

[1] M. Boulkeroua and A. Stark, "On the determinants of the sensitivity of the yield spread of corporate bonds to changes in the level and slope of the yield curve," in Proceedings of the IV world finance conference, pp. 118-167, Rhodes, Greece, July 2013.

[2] D. Sraer and V. Haddad, "The banking view of bond risk premia," Society for Economic Dynamics, vol. 814, 2016.

[3] B. Dupoyet, X. Jiang, and Q. Zhang, "A new take on the relationship between interest rates and credit spreads," Technical report, Working paper of Florida International University, Miami, FL, USA, 2018, http://faculty.fiu.edu/ $\sim$ dupoyetb/credit_spreads_heteroskedasticity.pdf.

[4] R. C. Merton, "On the pricing of corporate debt: the risk structure of interest rates," The Journal of Finance, vol. 29, no. 2, pp. 449-470, 1974.

[5] I. Loncarski and P. G. Szilagyi, "Empirical analysis of credit spread changes of US corporate bonds," International Review of Financial Analysis, vol. 24, pp. 12-19, 2012. 
[6] S. B. Kamin and K. von Kleist, The Evolution and Determinants of Emerging Markets Credit Spreads in the 1990s, Bank of International Settlements, Basel, Switzerland, 1999, https:// ssrn.com/abstract $=850104$.

[7] B. Eichengreen and A. Mody, "Lending booms, reserves and the sustainability of short-term debt: inferences from the pricing of syndicated bank loans," Journal of Development Economics, vol. 63, no. 1, pp. 5-44, 2000.

[8] J. Hilscher and Y. Nosbusch, "Determinants of sovereign risk: macroeconomic fundamentals and the pricing of sovereign debt*," Review of Finance, vol. 14, no. 2, pp. 235-262, 2010.

[9] M. Gubareva and R. Borges, "Switching interest rate sensitivity regimes of U.S. Corporates," The North American Journal of Economics and Finance, 2019, In press.

[10] M. Gubareva, "Historical interest rate sensitivity of emerging market sovereign debt: evidence of regime dependent behavior," Annals of Economics and Finance, vol. 19, no. 2, pp. 405-442, 2018.

[11] M. Gubareva and M. R. Borges, "Binary interest rate sensitivities of emerging market corporate bonds," The European Journal of Finance, vol. 24, no. 17, pp. 1569-1586, 2018 a.

[12] Basel Committee on Banking Supervision, "Standards: interest rate risk in the banking book. Bank for International Settlements," 2016, https://www.bis.org/bcbs/publ/d368.pdf.

[13] European Banking Authority (EBA), "Guidelines on the management of interest rate risk arising from non-trading activities," 2018, http://www.eba.europa.eu.

[14] Committee on the Global Financial System (CGFS), "Financial stability implications of a prolonged period of low interest rates," CGFS Paper No 61, https://www.bis.org/publ/ cgfs61.pdf, 2018.

[15] H. G. Fong and O. A. Vasicek, "A risk minimizing strategy for portfolio immunization," The Journal of Finance, vol. 39, no. 5, pp. 1541-1546, 1984.

[16] I. Welch, Corporate Finance: An Introduction, Student Value Edition Plus Myfinancelab Student Access Kit, Prentice-Hall, Upper Saddle River,NJ, USA, 2008.

[17] M. Gubareva and M. R. Borges, "Typology for flight-to-quality episodes and downside risk measurement," Applied Economics, vol. 48, no. 10, pp. 835-853, 2016.

[18] M. Gubareva and M. R. Borges, "Rethinking economic capital management through the integrated derivative-based treatment of interest rate and credit risk," Annals of Operations Research, vol. 266, no. 1-2, pp. 71-100, 2018.

[19] A. Ang and G. Bekaert, "Regime switches in interest rates," Journal of Business \& Economic Statistics, vol. 20, no. 2, pp. 163-182, 2002.

[20] A. Ang and A. Timmermann, "Regime changes and financial markets," Annual Review of Financial Economics, vol. 4, no. 1, pp. 313-337, 2012.

[21] M. Guidolin, "Markov switching models in empirical finance," in Missing Data Methods: Time-Series Methods and Applications, pp. 1-86, Emerald Group Publishing Limited, Bingley, UK, 2011.

[22] A. Mikaelian, "Cycle-adjusted capital market expectations under black-litterman framework in global tactical asset allocation," Review of Business and Economics Studies, vol. 1, no. 1, pp. 89-99, 2013.

[23] M. M. Andreasen, T. Engsted, S. V. Møller, and M. Sander, "Bond market asymmetries across recessions and expansions: new evidence on risk premia (6-9-2017)," CREATES Research Paper 2016-26, https://ssrn.com/abstract=2834898 or http://dx.doi.org/10.2139/ssrn.2834898, 2017. 